\title{
Effects of vitamin D supplementation on alveolar macrophage gene expression: preliminary results of a randomized, controlled trial
}

\author{
Alicia K Gerke ${ }^{\text {* }}$, Alejandro A Pezzulo ${ }^{1}$, Fan Tang ${ }^{2}$, Joseph E Cavanaugh² ${ }^{2}$ Thomas B Bair ${ }^{3}$, Emily Phillips ${ }^{1}$, \\ Linda S Powers ${ }^{1}$ and Martha M Monick ${ }^{1}$
}

\begin{abstract}
Background: Vitamin D deficiency has been implicated as a factor in a number of infectious and inflammatory lung diseases. In the lung, alveolar macrophages play a key role in inflammation and defense of infection, but there are little data exploring the immunomodulatory effects of vitamin D on innate lung immunity in humans. The objective of this study was to determine the effects of vitamin D supplementation on gene expression of alveolar macrophages.

Methods: We performed a parallel, double-blind, placebo-controlled, randomized trial to determine the effects of vitamin D on alveolar macrophage gene expression. Vitamin D3 (1000 international units/day) or placebo was administered to adults for three months. Bronchoscopy was performed pre- and post-intervention to obtain alveolar macrophages. Messenger RNA was isolated from the macrophages and subjected to whole genome exon array analysis. The primary outcome was differential gene expression of the alveolar macrophage in response to vitamin D supplementation. Specific genes underwent validation by polymerase chain reaction methods.

Results: Fifty-eight subjects were randomized to vitamin $D(n=28)$ or placebo $(n=30)$. There was a marginal overall difference between treatment group and placebo group in the change of 25 -hydroxyvitaminD levels ( $4.43 \mathrm{ng} / \mathrm{ml}$ vs. $0.2 \mathrm{ng} / \mathrm{ml}, \mathrm{p}=0.10$ ). Whole genome exon array analysis revealed differential gene expression associated with change in serum vitamin D levels in the treated group. CCL8/MCP-2 was the top-regulated cytokine gene and was further validated.
\end{abstract}

Conclusions: Although only a non-significant increased trend was seen in serum vitamin D levels, subjects treated with vitamin D supplementation had immune-related differential gene expression in alveolar macrophages.

Trial registration: ClinicalTrials.org: NCT01967628.

Keywords: Alveolar, Gene expression, Immunity, Innate, Macrophages, Randomized controlled, Vitamin D

\section{Background}

Vitamin D is suspected to be an important factor in susceptibility to bacterial and viral infections of the lung [1]. Historically, Vitamin D has been used as a treatment for tuberculosis [2]. More recently, deficiency has been associated with influenza, increased severity of community acquired pneumonia and development of chronic obstructive pulmonary disease (COPD) [3-5]. The mechanisms

\footnotetext{
* Correspondence: alicia-gerke@uiowa.edu

'Department of Internal Medicine, University of lowa, 200 Hawkins Dr, lowa City 52242, IA, USA

Full list of author information is available at the end of the article
}

behind these effects are unclear, but may reflect, in part, the effects of vitamin $\mathrm{D}$ on the innate immune response of the lung.

Prior studies have indicated that vitamin D plays an important intracrine role in serum monocyte and macrophage response to infection [6]. Macrophages, monocytes, T-cells, and dendritic cells express 1-alpha-hydroxylase which converts 25 -hydroxyvitamin $\mathrm{D}(25(\mathrm{OH}) \mathrm{D})$ to its active form 1,25-dihydroxyvitamin D (1,25(OH)D). Macrophages constitutively express the vitamin $\mathrm{D}$ receptor and serum macrophages have been shown to enhance innate immunity by vitamin $\mathrm{D}$ regulated production of cathelicidin 
in response to mycobacteria [7]. Vitamin D-regulated human cathelicidin production also promotes autophagy of the macrophage, an important process in removing infectious antigens [8].

Despite these reports of the importance of vitamin D in serum macrophages, there are few data regarding the specific relationship of the alveolar macrophage to vitamin D status or supplementation. In this study, the objective was to determine how vitamin $\mathrm{D}$ regulates lung innate immunity. We performed a double-blind, placebo controlled, randomized trial in humans to investigate the effects of vitamin D on alveolar macrophage gene expression. The hypothesis was that vitamin D supplementation will affect the gene expression profile of the alveolar macrophage in human subjects.

\section{Methods}

\section{Trial design}

This study was performed as a specific analysis of a double-blind, parallel-group, randomized controlled intervention study of the effects vitamin D on alveolar macrophage gene expression in both smoking and nonsmoking subjects. The study was approved by the institutional review board at the University of Iowa (IRB\# 200607708) and written consent was obtained from all subjects. The study is registered on ClinicalTrials.org (NCT01967628). An independent data safety monitoring board met regularly to review safety and occurrence of adverse events. The study was monitored by the sponsoring agency to evaluate study progress, quality of data collection, and adherence to regulatory and study protocols.

\section{Participants}

Subjects were included if they were 18-60 years old and able to understand and sign a consent form. Subjects were recruited from the community via advertisements and word-of-mouth. Subjects were excluded if they had taken a multivitamin or vitamin D supplement within the previous three months, were pregnant or breastfeeding, had a vaccination within one month, had a history of asthma, diabetes, heart disease, allergy to lidocaine, or any other medical problem that would increase risk of bronchoscopy (e.g. renal disease or electrolyte imbalance). Subjects were also excluded if they had a respiratory infection in the six weeks prior to enrollment, history of pneumonia within three years, history of positive tuberculin skin test, or use of antibiotics for any purpose within six weeks of enrollment. Subjects were excluded if they were taking any prescription medication except for hormonal birth control, topical medications for mild skin ailments, selected antidepressants, levothyroxine, as needed acid reflux treatment, as needed over-the-counter antihistamine, or as needed sleep aids.

\section{Intervention}

After obtaining informed consent, included subjects underwent randomization to 1000 international units (IU) per day of cholecalciferol (Vitamin D3) by oral capsule or a matching placebo capsule for a three-month period of time (total dose of 90,000 IU). Prior to treatment, each subject underwent bronchoscopy with bronchoalveolar lavage to obtain alveolar macrophages. After three months of treatment with vitamin $\mathrm{D}$ or placebo, each subject then underwent a second bronchoscopy to obtain alveolar macrophages. Bronchoscopies were performed by a pulmonary physician in standard fashion using a flexible bronchoscope (model P160 or P180; Olympus) at the University of Iowa Hospitals and Clinics (Iowa City, Iowa, USA) between May 2008 and July 2010. Subjects were premedicated with either morphine 10 milligrams (mg) or meperidine $12.5-25 \mathrm{mg}$ intramuscularly and atropine $0.6 \mathrm{mg}$ intramuscularly prior to bronchoscopy. Subjects did have the option of foregoing premedication. Subjects were then administered topical anesthesia with $2 \%-4 \%$ lidocaine to numb the airway. Under standard clinical monitoring, the bronchoscope was introduced trans-nasally or transorally into the right lung. To collect alveolar macrophages, bronchoalveolar lavage was performed by instilling five aliquots of 20 milliliters of sterile normal saline into three segments of the lung and suctioning back into a trap container. Blood was drawn at each subject visit prior to bronchoscopy to assess for levels of $25(\mathrm{OH}) \mathrm{D}, 1,25(\mathrm{OH}) \mathrm{D}$, parathyroid hormone, calcium, and creatinine. Women of childbearing potential underwent urine pregnancy screen prior to each bronchoscopy.

\section{Outcomes}

The primary outcome was to assess the effects of vitamin D supplementation on differential gene expression as determined by microarray analysis of alveolar macrophage messenger RNA (mRNA). Gene expression was compared between placebo and treatment groups, as well as a paired analysis pre- and post-supplementation within the group treated with vitamin D.

\section{Randomization}

Subjects were randomized on a 1:1 basis to Vitamin D3 or a matching placebo capsule by a computer generated randomization list provided by the data coordinating center. Each study participant was assigned to a study product allocation number by the data coordinating center after study consent. Study participants, clinical research team, sponsoring agency, and data analysts were blinded to intervention assignment. The vitamin D and placebo were identical in appearance.

\section{Statistical analysis: clinical data}

All clinical data analysis was conducted using SAS version 9.1.3 (SAS Institute, Inc., Cary, North Carolina). To confirm 
whether the randomization scheme worked in our study, the two sample $T$-test was used to compare whether there were differences in two treatment groups for all the continuous demographic variables. The $T$-test was also used to investigate between-group differences in clinical outcomes. The Fisher's Exact test was used for gender to test whether the assignment was balanced.

\section{Preparation of RNA and microarray analysis}

RNA preparation, quality analysis, and microarray analysis were done as previously described [9]. Measurements of genome-wide macrophage mRNA expression were conducted using the GeneChip Human Exon 1.0 ST Arrays (Affymetrix). Microarray data were analyzed with Partek Genomics Suite, version 6.5, software (Partek, St. Louis, MO, USA). The data were assessed for quality and subjected to robust multi-array averaging normalization. The method of statistical analysis was the paired $T$-test (before vitamin D supplementation versus after vitamin D supplementation in the treated group). A p of $10^{-5}$ was considered significant in this analysis. Gene pathway analysis was conducted using the GoMiner suite (Genomics and Bioinformatics Group, Bethesda, MD, USA) of algorithms. The expression data has been deposited in NCBI Geo repository.

\section{Gene validation and analysis}

Three candidate genes, chosen for biological plausibility and statistical significance, were validated by polymerase chain reaction (PCR). The genes, CCL8, P2RY10, and SOX13 were analyzed in samples from subjects whose serum 25(OH)D levels rose greater than $5 \mathrm{ng} / \mathrm{ml}$. Total RNA (300 ng) was reverse-transcribed to cDNA using iScript cDNA Synthesis kit (Bio-Rad). SYBR Green-based quantitative PCR reactions (BioRad) were performed as previously described [9]. Specificity of the amplification was confirmed using melting curve analysis. Expression levels were defined as a ratio between the threshold cycle $(\mathrm{Ct})$ values of CCL8, P2RY10, SOX13 and the endogenous control, HPRT.

\section{Results}

\section{Overall distribution of subjects}

105 human subjects were enrolled (Figure 1) between May 2008 and July 2010. The trial was completed after a predetermined endpoint of time was achieved. After signing informed consent, seven of the enrolled subjects were found to have exclusion criteria and were not randomized. Ninety-eight subjects were randomized to intervention. Thirteen subjects were terminated early. For the purposes of this analysis, we excluded 27 subjects who smoked from the analysis, as smoking has known profound effects on macrophage gene expression. For the final analysis, 58 subjects were included.

\section{Clinical outcomes}

Demographics and labs, stratified by treatment group (Vitamin D versus Placebo), of the 58 subjects who were analyzed are described in Table 1 . There were no differences in age or lab values between treated and placebo groups, indicating that randomization was effective. There were marginal overall differences between treatment and placebo groups in the change of $25(\mathrm{OH}) \mathrm{D}$ level ( $\mathrm{p}$-value $=0.10)$ and parathyroid hormone level $(\mathrm{p}=0.05)$, but no significant changes in 1,25(OH)D levels or calcium levels (Table 2). Figure 2 shows the distribution of the change of $25(\mathrm{OH}) \mathrm{D}$ levels by treatment group.

\section{Gene expression}

Paired analysis was performed on the group treated with vitamin D (pre- and post-supplementation) (Table 3). There were seven genes with $\mathrm{P}$ less than $10^{5}$ : Putative P2Y purinoceptor 10 (NM_014499), monocyte chemoattractant protein 2 (CCL8/MCP-2)(NM_005623), Homer protein homolog 2 (NM_199330), asparaginyl-tRNAsynthetase 2 (NM_024678), Ras association (RalGDS/AF-6) domain family member (NM_014737), SRY (Sex Determining Region Y)-Box 13 (NM_005686), Melanocortin 3 receptor (NM_019888). Only the monocyte chemoattractant protein 2 (CCL8/MCP-2) had a fold-change of greater than 1.5. Pathway analysis showed differentially regulated immune pathways, but all had a false discovery rate of greater than 0.25 (Table 4). There were no significant differences in alveolar macrophage gene expression between treated and placebo groups.

\section{Gene validation}

To validate the array data we chose three genes based on plausibility and significance (two upward trending, and one downward trending) in the paired analysis of the treated group. We found that with all three genes, the individual assays $(n=11)$ replicated the change trends found in the array data (Figure 3).

\section{Safety and adverse events}

There were fourteen total adverse events reported among eight of the subjects: nine events in placebo group and five events in the vitamin D treated group. There were no serious adverse events or procedure-related adverse events among the 58 subjects. Indigestion after taking the study drug was the only study-related adverse event in a patient taking vitamin D. Adverse events determined to be unrelated to the study included epididymitis, urinary tract infection, increased worry, irritability and/or depression, complication of an unrelated medical procedure during the study period, abnormal vaginal bleeding, uterine cramping, and head injury.

\section{Compliance}

In the treatment group, thirteen subjects (46\%) completed full therapy, and eleven (39\%) of subjects had residual 


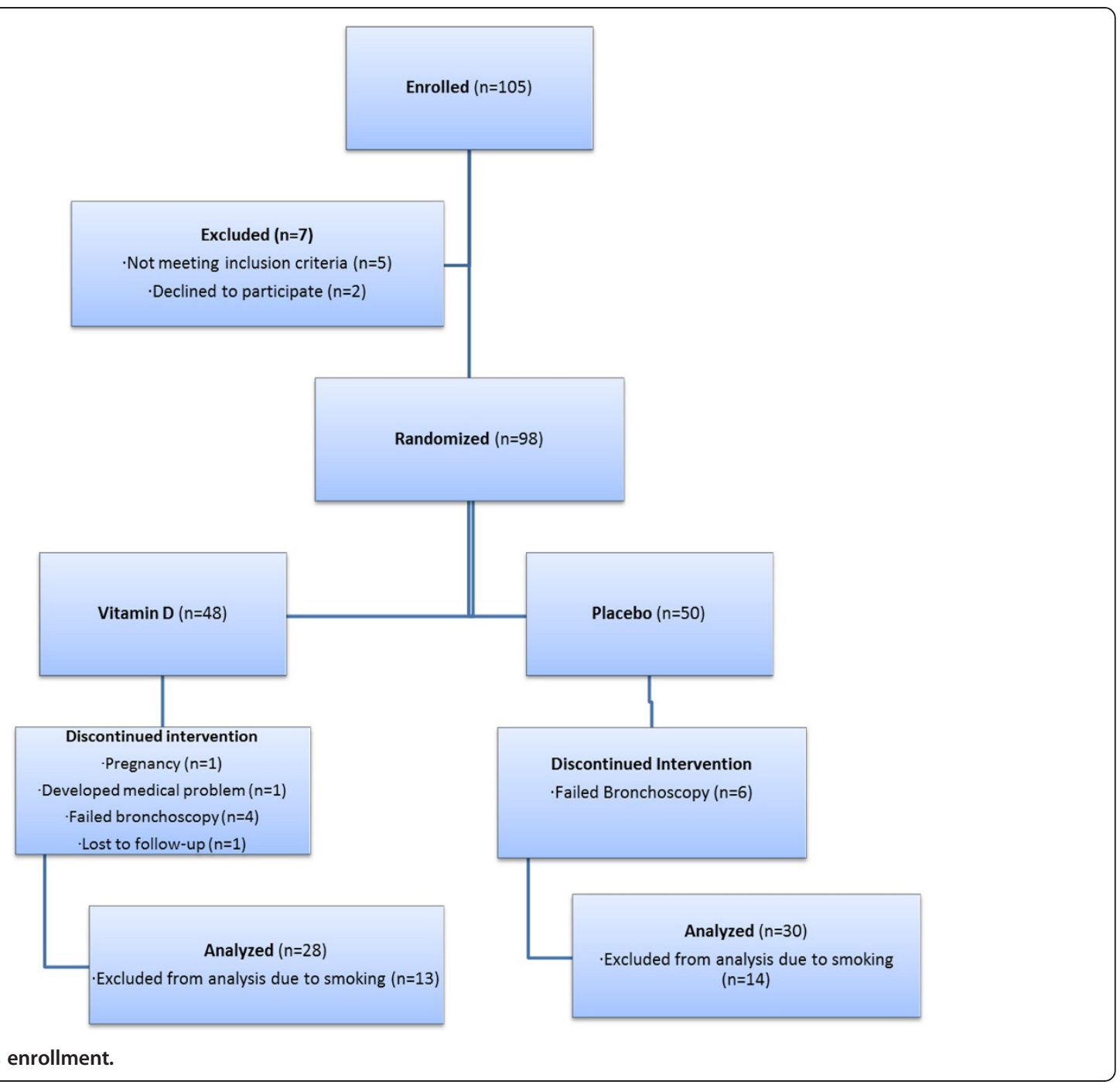

doses. Among those that did not take full dose, the average number of missed capsules was 6.5 capsules (range 1-15), equating to an average total missed dose of 6500 IU. Four treated subjects did not bring back their pill bottles for compliance analysis. In the placebo group, thirteen subjects

Table 1 Comparison of patient's characteristics by treatment group: vitamin D treatment versus placebo

\begin{tabular}{cccc}
\hline Variable & $\begin{array}{c}\text { Placebo } \\
\text { group }\end{array}$ & $\begin{array}{c}\text { Treatment } \\
\text { group }\end{array}$ & $\mathbf{P}$ \\
\hline Age (years) & 26.3 & 25.6 & 0.72 \\
Baseline 25(OH) ${ }^{*}$ level $(\mathrm{ng} / \mathrm{ml})$ & 32.9 & 30.9 & 0.56 \\
Baseline 1,25(OH)D ${ }^{\dagger}$ level $(\mathrm{pg} / \mathrm{ml})$ & 49.3 & 51.2 & 0.67 \\
Baseline parathyroid hormone $(\mathrm{pg} / \mathrm{ml})$ & 34.9 & 36.8 & 0.57 \\
Baseline calcium level $(\mathrm{mg} / \mathrm{dl})$ & 9.2 & 9.1 & 0.47 \\
Male gender $(\%)$ & $36.7 \%$ & $63.3 \%$ & 0.20 \\
\hline
\end{tabular}

*25-hydroxyvitamin $\mathrm{D}$.

${ }^{\dagger} 1,25$-hydroxyvitamin $\mathrm{D}$. completed full therapy (43\%) and sixteen subjects (53\%) had missed doses. The average number of missed capsules was 8.8 (range 1-30). One placebo subject did not bring back the pill bottle for analysis.

\section{Discussion}

In this study, we used microarray technology to determine gene expression differences in human subjects treated with vitamin D supplementation. Although the results were not

\section{Table 2 Treatment effect of vitamin D supplementation}

\begin{tabular}{cccc}
\hline Variable & $\begin{array}{c}\text { Placebo } \\
\text { group }\end{array}$ & $\begin{array}{c}\text { Treatment } \\
\text { group }\end{array}$ & $\mathbf{P}$ \\
\hline Change in $25(\mathrm{OH}) \mathrm{D}^{*}$ level $(\mathrm{ng} / \mathrm{ml})$ & 0.20 & 4.43 & 0.10 \\
Change in $1,25(\mathrm{OH}) \mathrm{D}^{\dagger}$ level $(\mathrm{pg} / \mathrm{ml})$ & 1.13 & -3.71 & 0.30 \\
Change in parathyroid hormone $(\mathrm{pg} / \mathrm{ml})$ & 7.83 & 1.21 & 0.05 \\
Change in calcium level $(\mathrm{mg} / \mathrm{dl})$ & -0.10 & 0.01 & 0.24 \\
\hline
\end{tabular}

*25-hydroxyvitamin D.

${ }^{\dagger} 1,25$-hydroxyvitamin $D$. 


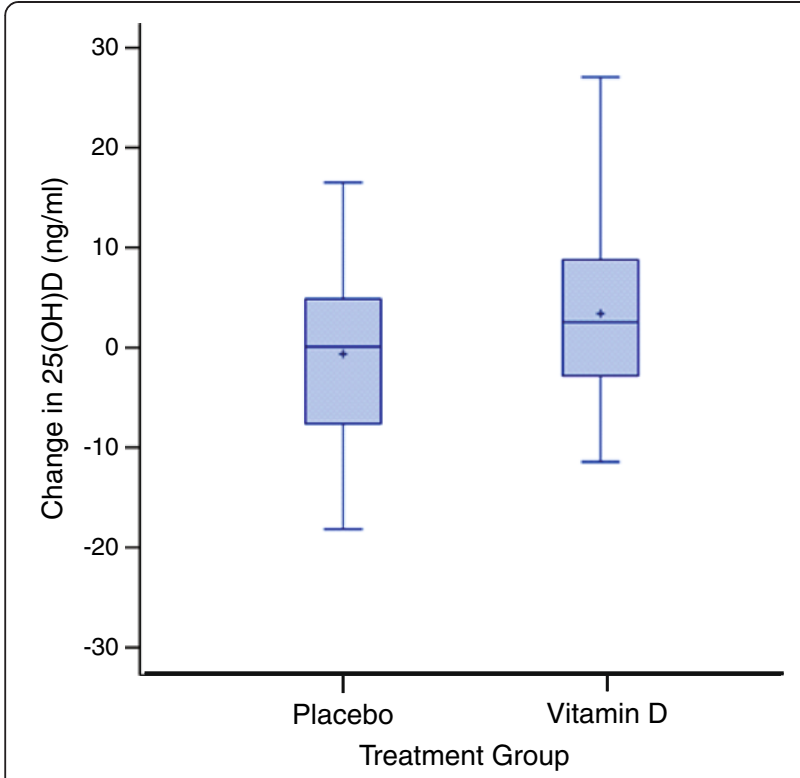

Figure 2 Treatment effect for 25-hydroxyvitamin $D(25(\mathrm{OH}) \mathrm{D})$ levels by treatment group (vitamin $D$ versus placebo) $(p=0.10)$.

statistically strong, trends show that there are small differences in resting alveolar macrophage gene expression modulated by vitamin D supplementation. To our knowledge, this is the first study that shows the effects of vitamin D supplementation on alveolar macrophage gene expression in a clinical trial in humans.

The importance of vitamin D in bone health is wellestablished and has been the standard by which adequate serum levels and supplementation have been based. The effects on the non-classical roles of vitamin $\mathrm{D}$ in autoimmune disease, cancer, and immunity have sparked intense controversy over the past decade. It is unknown whether higher recommended daily doses are needed, or what the 'normal' 25(OH)D level should be. In immunity, the question of whether vitamin $\mathrm{D}$ effects are primarily anti-inflammatory or antimicrobial is unclear, and data regarding its effects supporting both innate and adaptive immunity exist $[10,11]$. For innate immunity, vitamin $D$ has been shown to enhance the immune response to infection by increasing cathelicidin and phagocytosis in serum macrophages, important mechanisms in fighting infection [7]. Since alveolar macrophages and airway epithelial cells are able to convert vitamin D to its active form, it is plausible that this type of antimicrobial action is also present in the lung [12]. However, to date, randomized controlled trials on whether vitamin D supplementation decreases the incidence of respiratory infections have been conflicting in various populations [13-15].

Our strongest upregulated inflammatory gene is monocyte chemoattractant protein 2 (CCL8/MCP-2). CCL8 is a chemokine involved in attracting human leukocytes,
Table 3 The thirty most differentially regulated genes in subjects treated with vitamin D supplementation (pre- versus post-supplementation)

\begin{tabular}{|c|c|c|c|}
\hline RefSeq & Gene symbol & $\mathbf{P}$ & Fold change \\
\hline NM_014499 & P2RY10 & $1.45 \mathrm{E}-05$ & 1.30 \\
\hline NM_005623 & CCL8 & 1.99E-05 & 1.51 \\
\hline NM_199330 & HOMER2 & $2.11 \mathrm{E}-05$ & 1.25 \\
\hline NM_024678 & NARS2 & $2.16 \mathrm{E}-05$ & 1.23 \\
\hline NM_014737 & RASSF2 & $2.86 \mathrm{E}-05$ & 1.15 \\
\hline NM_005686 & SOX13 & 8.37E-05 & -1.12 \\
\hline NM_019888 & MC3R & 9.95E-05 & 1.41 \\
\hline NM_173079 & RUNDC1 & 0.00017 & 1.97 \\
\hline NM_000693 & ALDH1A3 & 0.00019 & 1.22 \\
\hline NM_024839 & RPP21 & 0.00022 & -1.35 \\
\hline NM_198562 & C3orf62 & 0.00022 & -1.21 \\
\hline NM_005164 & $A B C D 2$ & 0.00027 & 1.16 \\
\hline NM_017649 & CNNM2 & 0.00028 & 1.19 \\
\hline NM_014240 & LIMD1 & 0.00028 & -1.18 \\
\hline NM_004123 & GIP & 0.00030 & 1.27 \\
\hline NM_001040653 & ZXDC & 0.00031 & -1.20 \\
\hline NM_001100389 & TMEM192 & 0.00033 & -1.14 \\
\hline NM_207111 & RNF216 & 0.00033 & -1.18 \\
\hline NM_014033 & METTL7A & 0.00035 & 1.18 \\
\hline NM_014751 & MTSS1 & 0.00036 & 1.14 \\
\hline NM_002145 & HOXB2 & 0.00037 & 1.20 \\
\hline NM_144669 & GLT1D1 & 0.00037 & 1.20 \\
\hline AF258559 & LYRM4 & 0.00040 & -1.79 \\
\hline NM_002258 & KLRB1 & 0.00046 & 1.28 \\
\hline NM_145178 & ATOH7 & 0.00048 & 1.22 \\
\hline NM_006545 & NPRL2 & 0.00048 & -1.11 \\
\hline NM_015550 & OSBPL3 & 0.00048 & -1.14 \\
\hline NM_003239 & TGFB3 & 0.00051 & 1.18 \\
\hline NM_001719 & BMP7 & 0.00054 & 1.17 \\
\hline AY204749 & NCRNA00114 & 0.00055 & 1.27 \\
\hline
\end{tabular}

Table 4 Top differentially regulated gene pathways in treated subjects pre- versus post-supplementation*

\begin{tabular}{llll}
\hline $\begin{array}{l}\text { Differentially regulated } \\
\text { gene pathways }\end{array}$ & Size & $\begin{array}{l}\text { Enrichment } \\
\text { score }\end{array}$ & $\begin{array}{l}\text { Normalized } \\
\text { enrichment } \\
\text { score }\end{array}$ \\
\hline Insulin growth factor-1/mTOR pathway & 20 & 0.59 & 1.41 \\
Calcineurin pathway & 18 & 0.57 & 1.35 \\
Rac1 pathway & 22 & 0.55 & 1.32 \\
Interleukin-10 anti-inflammatory pathway & 17 & 0.56 & 1.30 \\
B-cell receptor pathway & 33 & 0.51 & 1.28 \\
Cytokine pathway & 21 & 0.53 & 1.27 \\
Caspase pathway & 23 & 0.52 & 1.27 \\
\hline
\end{tabular}

*All pathways have false discovery rate of greater than 0.25 . 

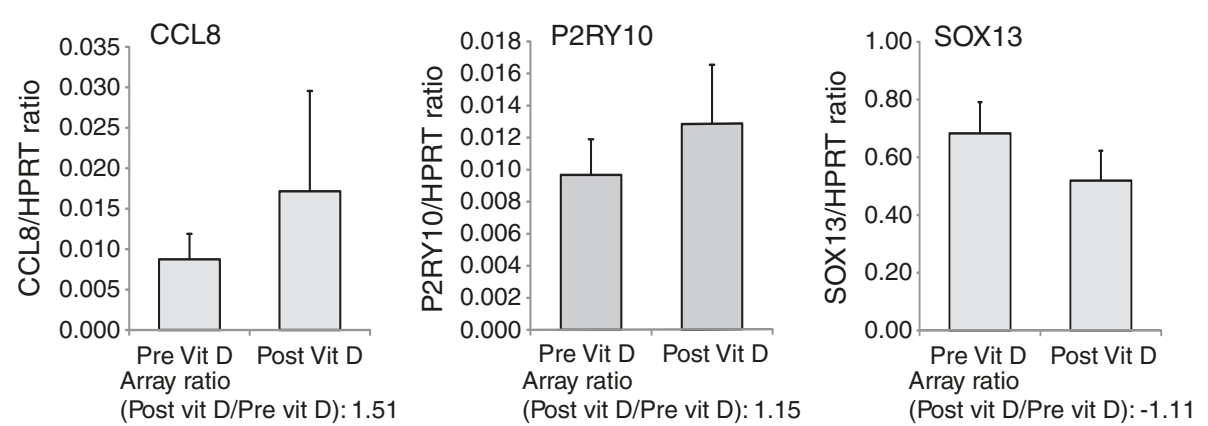

Figure 3 Comparison of pre and post supplementation mRNA of candidate genes in subjects treated with vitamin D whose 25-hydroxyvitamin D level rose greater than $5 \mathrm{ng} / \mathrm{ml}$ (measured by polymerase chain reaction).

lymphocytes, monocytes, natural killer cells, eosinophils, and basophils via a number of receptors. It is also thought to be a potent inhibitor of HIV through through its action on the CCL5 (chemokine ligand 5) [16]. CCL8 has been found to be elevated in tuberculosis infection and proposed as a potential biomarker of tuberculous pleural effusions [17-19]. Prior studies have indicated effects of vitamin D on suppression of MCP-1 and inflammation, but there have been no prior reported studies that we are aware showing a relationship between vitamin D and CCL8/MCP-2 [20,21]. Given the importance of CCL8 in anti-viral and antituberculous activity, this cytokine warrants further study in relation to vitamin $\mathrm{D}$ and the lung.

There are a number of factors that may have affected our results towards a less robust gene expression analysis. First of all, despite good compliance with treatment, the amount of vitamin D supplementation was not enough to uniformly raise serum 25(OH)D levels in all of our subjects, and thereby, likely diluted the true effects of vitamin D. This may be similar to prior study showing no difference in outcomes in subjects with tuberculosis treated with vitamin D; however, the treated patients did not show an increase in their vitamin D levels [22]. In our validation process, we tested the gene expression of the candidate genes in the patients who increased their 25(OH)D levels and were able to show a more pronounced effect. Paired analysis of the treated group showed more significant differences in gene expression, as it likely reduced the baseline subject variability. Another limitation is that the alveolar macrophages were harvested in steady state without stimulation by antigens or microbes that may be needed to promote vitamin D-regulated transcription. Next, our subject population was relatively young, limiting generalizability to older or elderly populations. Lastly, our sample size may have not been large enough, with high variability within groups, to provide power to this type of complex whole genome analysis. Future research is warranted with clinical trials with further refinement of patient groups, increased sample size, and protocol methods to ensure enough vitamin D to raise serum vitamin D levels. Given the number of vitamin D insufficient or deficient people in the population, research on vitamin D's effects on immunity could have important public health implications.

\section{Conclusions}

In conclusion, we found small, but potentially important, differences in gene expression of the resting alveolar macrophage in human subjects supplemented with vitamin D. The results of this study, both of the microarray analysis and the lessons learned in the trial methods, will help design future studies to evaluate the effects of vitamin $\mathrm{D}$ on lung innate immunity. Future studies need to focus on the correlation of effects with serum $25(\mathrm{OH}) \mathrm{D}$ levels, the response of activated alveolar macrophages to vitamin $\mathrm{D}$, and effects related to gender, age, and race.

\section{Availability of supporting data}

The data sets supporting the results of this article are available in the National Center for Biotechnology Information (NCBI) gene expression omnibus (GEO) repository: accession number GSE56583, http://www.ncbi.nlm. nih.gov/geo/query/acc.cgi?acc=GSE56583.

\section{Abbreviations}

25(OH)D: 25-hydroxyvitamin D; 1,25(OH)D: 1,25- hydroxyvitamin D; CCL5: Chemokine ligand 5; CCL8: Chemokine ligand 8; IU: International units; MCP: Monocyte chemoattractant protein; Mg: Milligrams; mRNA: Messenger RNA; PCR: Polymerase chain reaction.

\section{Competing interests}

The authors declare that they have no competing interests.

\section{Authors' contributions}

AKG, the guarantor of the manuscript, contributed to the design of the study, was responsible for data collection and analyses, and contributed to the writing and revising all drafts of the manuscript. AAP was responsible for data analyses, and contributed to the writing and revising of the manuscript. FT was responsible for data analyses, and contributed to writing and revising of the manuscript. TBB was responsible for data analyses, and contributed to revising the manuscript. JEC contributed to data analyses, and to the writing and revising of the manuscript. EP was responsible for study implementation, data collection, analysis and revising of the manuscript. LSP contributed to data collection, analyses, and to the writing and revising of the manuscript. MMM contributed to the original design of the study, data collection and analyses, 
and to the writing and revising of the first draft and subsequent drafts of the manuscript. All authors contributed to final approval of the manuscript.

\section{Research funding}

This project was funded by the National Institutes of Health $(\mathrm{NIH})$, NO1-Al-30040-01, NIH RO1 HL096625, and R21HL109589 to M. M. and by the National Institute for Environmental Health Sciences through the University of lowa Environmental Health Sciences Research Center, NIEHS/NIH P30 ES005605 and Grant Number UL1RR024979 from the National Center for Research Resources (NCRR), a part of the NIH. AKG is funded by a career development award from the $\mathrm{NIH/NHLBl}$, grant number $\mathrm{K} 23 \mathrm{HL} 114640-01$. The funding sources did not have a role in the design, collection, analysis, interpretation, writing, or decision to submit the manuscript.

\section{Author details}

${ }^{1}$ Department of Internal Medicine, University of lowa, 200 Hawkins Dr, lowa City 52242, IA, USA. ${ }^{2}$ Department of Biostatistics, University of lowa, 105 River Street, lowa City 52242, IA, USA. ${ }^{3}$ University of lowa Institute for Human Genetics, lowa City, IA, USA.

Received: 14 January 2014 Accepted: 13 March 2014

Published: 26 March 2014

\section{References}

1. Beard JA, Bearden A, Striker R: Vitamin D and the anti-viral state. J Clin Virol 2011, 50:194-200

2. Martineau AR: Old wine in new bottles: vitamin $D$ in the treatment and prevention of tuberculosis. Proc Nutr Soc 2012, 71:84-89.

3. Cannell JJ, Vieth R, Umhau JC, Holick MF, Grant WB, Madronich S, Garland CF, Giovannucci E: Epidemic influenza and vitamin D. Epidemiol Infect 2006, 134:1129-1140.

4. Janssens W, Bouillon R, Claes B, Carremans C, Lehouck A, Buysschaert I, Coolen J, Mathieu C, Decramer M, Lambrechts D: Vitamin D deficiency is highly prevalent in COPD and correlates with variants in the vitamin D-binding gene. Thorax 2010, 65:215-220.

5. Youssef DA, Miller CW, El-Abbassi AM, Cutchins DC, Cutchins C, Grant WB, Peiris AN: Antimicrobial implications of vitamin D. Dermatoendocrinol 2011, 3:220-229

6. Hewison M: Vitamin $\mathrm{D}$, and the intracrinology of innate immunity. Mol Cell Endocrinol 2010, 321:103-111.

7. Liu PT, Stenger S, Li H, Wenzel L, Tan BH, Krutzik SR, Ochoa MT, Schauber J, Wu K, Meinken C, Kamen DL, Wagner M, Bals R, Steinmeyer A, Zugel U, Gallo RL, Eisenberg D, Hewison M, Hollis BW, Adams JS, Bloom BR, Modlin RL: Toll-like receptor triggering of a vitamin D-mediated human antimicrobial response. Science 2006, 311:1770-1773.

8. Yuk JM, Shin DM, Lee HM, Yang CS, Jin HS, Kim KK, Lee ZW, Lee SH, Kim JM Jo EK: Vitamin D3 induces autophagy in human monocytes/macrophages via cathelicidin. Cell Host Microb 2009, 6:231-243.

9. Graff JW, Powers LS, Dickson AM, Kim J, Reisetter AC, Hassan IH, Kremens K, Gross TJ, Wilson ME, Monick MM: Cigarette smoking decreases global microRNA expression in human alveolar macrophages. PloS One 2012, 7:e44066.

10. Guillot X, Semerano L, Saidenberg-Kermanac'h N, Falgarone G, Boissier MC: Vitamin D and inflammation. Joint Bone Spine 2010, 77:552-557.

11. Bozzetto S, Carraro S, Giordano G, Boner A, Baraldi E: Asthma, allergy and respiratory infections: the vitamin D hypothesis. Allergy 2012, 67:10-17.

12. Hansdottir S, Monick MM, Hinde SL, Lovan N, Look DC, Hunninghake GW: Respiratory epithelial cells convert inactive vitamin $D$ to its active form: potential effects on host defense. J Immunol 2008, 181:7090-7099.

13. Jorde R, Witham M, Janssens W, Rolighed L, Borchhardt K, de Boer $\mathbb{H}$, Grimnes G, Hutchinson MS: Vitamin D supplementation did not prevent influenza-like illness as diagnosed retrospectively by questionnaires in subjects participating in randomized clinical trials. Scand J Infect Dis 2012, 44:126-132.

14. Rees JR, Hendricks K, Barry EL, Peacock JL, Mott LA, Sandler RS, Bresalier RS, Goodman M, Bostick RM, Baron JA: Vitamin D3 supplementation and upper respiratory tract infections in a randomized, controlled trial. Clin Infect Dis 2013, 57:1384-1392.

15. Urashima M, Segawa T, Okazaki M, Kurihara M, Wada Y, Ida H: Randomized trial of vitamin $D$ supplementation to prevent seasonal influenza $A$ in schoolchildren. Am J Clin Nutr 2010, 91:1255-1260.
16. Blaszczyk J, Coillie EV, Proost P, Damme JV, Opdenakker G, Bujacz GD, Wang $J \mathrm{M}$, Ji X: Complete crystal structure of monocyte chemotactic protein-2, a CC chemokine that interacts with multiple receptors. Biochemistry 2000, 39:14075-14081.

17. Liu H, Liu Z, Chen J, Chen L, He X, Zheng R, Yang H, Song P, Weng D, Hu H, Fan L, Xiao H, Kaufmann SH, Ernst J, Ge B: Induction of CCL8/MCP-2 by mycobacteria through the activation of tlr2/pi3k/akt signaling pathway. Plos One 2013, 8:e56815.

18. Maddocks S, Scandurra GM, Nourse C, Bye C, Williams RB, Slobedman B, Cunningham AL, Britton WJ: Gene expression in HIV-1/mycobacterium tuberculosis co-infected macrophages is dominated by M. Tuberculosis. Tuberculosis 2009, 89:285-293.

19. Ruhwald M, Bodmer T, Maier C, Jepsen M, Haaland MB, Eugen-Olsen J, Ravn P, TBNet: Evaluating the potential of IP-10 and MCP-2 as biomarkers for the diagnosis of tuberculosis. Eur Respir J 2008, 32:1607-1615.

20. Riek $A E$, Oh J, Bernal-Mizrachi C: $1,25(\mathrm{OH}) 2$ vitamin $\mathrm{D}$ suppresses macrophage migration and reverses atherogenic cholesterol metabolism in type 2 diabetic patients. J Steroid Biochem Mol Biol 2013, 136:309-312.

21. Gao D, Trayhurn P, Bing C: 1,25-dihydroxyvitamin D3 inhibits the cytokine-induced secretion of MCP-1 and reduces monocyte recruitment by human preadipocytes. Int J Obes 2013, 37:357-365.

22. Wejse C, Gomes VF, Rabna P, Gustafson P, Aaby P, Lisse IM, Andersen PL, Glerup H, Sodemann M: Vitamin D as supplementary treatment for tuberculosis: a double-blind, randomized, placebo-controlled trial. Am J Respir Crit Care Med 2009, 179:843-850.

doi:10.1186/2049-6958-9-18

Cite this article as: Gerke et al:: Effects of vitamin D supplementation on alveolar macrophage gene expression: preliminary results of a randomized, controlled trial. Multidisciplinary Respiratory Medicine 2014 9:18.

\section{Submit your next manuscript to BioMed Central and take full advantage of:}

- Convenient online submission

- Thorough peer review

- No space constraints or color figure charges

- Immediate publication on acceptance

- Inclusion in PubMed, CAS, Scopus and Google Scholar

- Research which is freely available for redistribution

Submit your manuscript at www.biomedcentral.com/submit
C Biomed Central 